YAK 342.5

ББК 67.400 .6

DOI 10.22394/1682-2358-2017-4-131-139

S.A. Komissarova, postgraduate student of the Political Sciences Department, Povolzbsky Institute of Management named after P.A. Stolypin, Branch of the Russian Presidential Academy of National Economy and Public Administration

\section{RESOURCE \\ AVAILABILITY \\ FOR DEPUTY \\ ACTIVITIES: \\ EXPERT ANALYSIS PRACTICE}

The problem of resource availability for different aspects of deputy activities is considered. The total of the resources used by deputies at the regional level is defined. The assessment of the political efficiency level of using different groups of resources by the example of the deputy corps is drawn. Features of the funding base of federal, regional, and local level deputies are revealed.

Key words and word-combinations: deputy practices funding, resource efficiency, deputy resource profile.
С.А. Комиссароßа, аспирант кафедрьг политических наук Поволжского института упрабления имени П.А. Стольтина - филиала Российской академии народного хозяйства и государственной службь при Президенте РФ (етаil: komissaro-va@yandex.ru)

\section{РЕСУРСООБЕСПЕЧЕННОСТЬ АЕПУТАТСКОЙ АЕЯТЕАЬНОСТИ: ОПЫТ ЭКСПЕРТНОГО АНААИЗА}

Аннотация. Рассматривается проблема ресурсной обеспеченности различных аспектов депутатской деятельности. Определяется совокупность ресурсов, используемых депутатами на региональном уровне. Дается оценка уровня политической эффективности использования разных групп ресурсов на примере депутатского корпуса Саратовской области. Выявляются особенности ресурсной базы депутатов федерального, регионального, местного уровней.

Ключевые слова и словосочетания: ресурсы депутатской деятельности, функциональность ресурсов, ресурсный профиль депутата.

P

есурсы депутатской деятельности - это все то, что можкет быть использовано народным избранником дмя реализации возложенных на него функциональных обязанностей, которые находятся в сфере пересечения интересов власти и общества. На наш взгляд, именно этот пограничный статус парламентской работы определяет специфику ресурсной базы пармаментария, которая сочетает 
в себе все многообразие общественных ресурсов, а также его цичных качеств. Цель данной статьи - определение совокупности ресурсов, используемых депутатами в деятельности, а также оџенка их политической эффективности, в частности в Саратовской области.

Анализ исскедовательской китературы, посвященной различным ресурсам, которые могут быть задействованы в политической сфере, позволяет составить оптимальный ресурсный портфель Аепутата, включающей институщиональные, неформально-сетевые, финансово-экономические, мичностно-профессиональные и медиаресурсы.

Институџиональные ресурсы предполагают прежде всего принадмежность депутата к политической партии, включенность народного избранника в систему парламентских структур (комитет, комиссию, непартийное депутатское объединение). В качестве дополнительных индикаторов проявления институционального фактора в деятельности парламентариев может быть использована широкая сеть общественных и государственных институтов [1]. Это внешние по отношению к мегислатуре среды, посредством которых пармаментарии могут расширять возможности своего позиџионирования в поцитическом пространстве, реализуя тот ици иной комплекс задач.

В группу неформально-сетевых ресурсов можкно включить всю совокупность социамьных компонентов (Сети, связи, доверие, реципрокность, кичная преданность), Аоступ к которым открывает депутатская деятельность, предоставляюшая народному избраннику новые возможности Аля укАонения от «правил ААя всех», расширения своего информационного пространства, получения доступа к нужным мюАям, кабинетам и коридорам, непосреАственного вкАючения в процесс принятия решений. Как правило, функщиональность социальных сетей скрыта от публики и находит свою реализацию в неформальных политических практиках, поощряя закрытость, кАановость, фаворитизм, семейственность, кАиентелизм и круговую поруку правящей эмиты в целом и депутатского корпуса в частности [2] .

Неотъемлемым компонентом деятельности депутата явмяются его финансовоэкономические ресурсы. Они адекватно вписаны в сложкившуюся сеть неформальных практик и отношений, в которую включен парламентарий, выступая в качестве и необходимого условия получения депутатом своего мандата, и действенного ресурса Аля обеспечения эффективной работы с избиратемями. Каждый депутат, реализуя свой мандат, задействует, с одной стороны, финансовые ресурсы, непосредственно связанные с его статусом, с Аругой - может использовать собственные экономические активы и пользоваться подлержкой предпринимательского сообщества. Безусловно, это ставит в неравное положкение всех депутатов, дополняя мегислатуру еще одним (финансово-экономическим) размомом [3] .

Без сомнения, важным ресурсом депутатской деятельности явмяются кичностные характеристики парламентария, его физические и духовные возможности, мобилизаџия которых обеспечивает реализаџию поведенческих стратегий в рамках поставленных задач и целевых ориентиров [4].

В качестве отдельного экономического актива, которым могут располагать депутаты в процессе своей деятельности в мегислатуре, выступают медиаресурсы. В этом случае информационные ресурсы можно рассматривать в качестве соџиального капитала депутата, используемого в процессе его деятельности. 
Информационный пул каждого парламентария представмяет собой целую группу изданий, с которыми у него на опредеменных условиях налажено взаимодействие [5, с. 22-26]. Формат информационного пула депутата и уровень организаџии работы со среАствами массовой информаџии позволяет сделать вывод об эффективности народного избранника, преломияя его активность в медиасфере в область коммуникаций с избирателями.

Анализ представленных ресурсов в данном исследовании осуществлялся в рамках экспертного опроса, проведенного в августе 2016 г. в Саратове и по которому автором составлены таблицы (табц. 1-3). В качестве экспертов выступали десять представителей органов власти, политологического сообщества и средств массовой информации. Им было предложено оценить функциональность преАставленных ресурсов, их соотношение в ресурсном профиле депутата, а также рассмотреть типовые карьерные модели парламентариев с точки зрения их ресурсного потенциала [6] .

Оџенивая функциональность различных видов ресурсов по пятибаммьной шкале ( 1 - минимальное, 5 - максимальное значение), эксперты отмечали их неравнозначную представленность в ресурсном профиле депутата, подчеркивая приоритет институџиональных и финансово-экономических ресурсов, которые, по мнению большинства, позволяют эффективно реализовывать депутатские полномочия и мандат народного избранника (табц. 1).

Таблица 1

Функциональность ресурсов в рамках депутатской деятельности (экспертные оџенки)

\begin{tabular}{l|c|c}
\hline \multicolumn{1}{c|}{ Группы ресурсов } & Оценки экспертов & Средняя оценка \\
\hline Институциональные ресурсы & $5,4,5,4,5,4,5,4,5,4$ & 4,5 \\
Неформально-сетевые ресурсы & $4,3,4,3,5,5,4,3,4,3$ & 3,8 \\
Финансово-экономические ресурсы & $5,5,5,5,5,5,5,5,5,5$ & 5,0 \\
Медиаресурсы & $4,4,4,5,4,3,5,4,4,3$ & 4,0 \\
Личностно-профессиональные ресурсы & $3,4,3,4,3,3,5,3,3,3$ & 3,4
\end{tabular}

Высокие показатели функщиональности институциональных и финансовоэкономических ресурсов эксперты объясняют прежде всего широким диапазоном возможностей их реализаџии на практике, неразрывностью связей экономической и политической сферы, а также универсальностью денег, экономических активов и политических институтов, потенциально способных существенно расширить ресурсную базу депутата главным образом за счет неформально-сетевых и информаџионных ресурсов.

В свою очередь, неформально-сетевые и медиаресурсы, по мнению большинства экспертов, явмяются производными от институциональных и финансово-экономических ресурсов, чем во многом объясняется их более низкий статус в иерархии ресурсов. Вместе с тем функциональность указанных ресурсов нельзя расценивать как ограниченную или второстепенную, поскольку 
в определенных условиях и при определенном режкиме использования они позволяют успешно решать поставленные переА депутатом задачи. Производность объясняется не иначе как необходимостью создания предварительных условий Аля накопиения данных ресурсов, чему способствуют, с оАной стороны, экономические возможности народного избранника, с Аругой - его вкцюченность в партийные и парламентские структуры.

Относительно невысокие оџенки уровня функциональности кичностно-профессиональных ресурсов эксперты объясняют не их периферийностью, а слабой выраженностью их в ресурсном профиле современного депутата, отмечая при этом несовершенство данной конструкции. При этом кичностные и профессиональные характеристики депутата в настоящее время оказались полностью замещенными институционацьными и финансово-экономическими ресурсами, а также отношениями кичной преданности, активно используемыми в качестве принципов формирования правящей элиты на различных уровнях власти. Во многом нивелирует мичностный и профессиональный профиль депутатов пропорциональная формула, которая получияа в последнее время широкое распространение на выборах в $е-$ гислатуру, особенно регионального и муниципального уровня.

Таким образом, обобщая мнения представителей экспертного сообщества, можно сконструировать пирамидальную модель ресурсного потенциала депутата. В фундаменте данной пирамиды находятся финансово-экономические и институциональные ресурсы, которые во многом выступают основой медиа- и сетевых ресурсов, расположенных на следующем уровне. Венчают конструкцию кичностно-профессиональные ресурсы парламентария, которые неотъемцемы от субъекта и явцяются не чем иным, как его человеческим капиталом, наработанным в ходе деятельности.

Важным выводом экспертов считается заключение о разАичных конструкциях ресурсной пирамиды на региональном и муниципальном уровне. По мнению респондентов, муниџипацьные депутаты в своей деятельности опираются на финансово-экономические ресурсы, дополняя их комплексом институциональных связей, мичностных и профессиональных качеств. Информационные и неформально-сетевые компоненты ресурсного потенциала в данном срезе парламентариев занимают отчетливые периферийные позиџии, которые в целом не влияют на результативность депутатской деятельности (табл. 2).

Таблииа 2

Функщиональность ресурсов в рамках депутатской деятельности на муниципальном уровне (экспертные оџенки)

\begin{tabular}{l|c|c}
\hline \multicolumn{1}{c|}{ Группы ресурсов } & Оценки экспертов & Средняя оценка \\
\hline Институциональные ресурсы & $4,4,3,4,3,3,3,3,4,3$ & 3,4 \\
Неформально-сетевые ресурсы & $3,3,2,3,3,2,3,4,3,3$ & 2,9 \\
Финансово-экономические ресурсы & $5,5,4,5,5,4,5,5,5,5$ & 4,8 \\
Медиаресурсы & $3,3,2,3,3,2,3,3,2,3$ & 2,7 \\
Личностно-профессиональные ресурсы & $4,3,3,3,4,3,4,3,3,4$ & 3,4
\end{tabular}


Финансово-экономический базис сохраняется в качестве основы ресурсного профиля депутата и на региональном уровне. ОАнако, в отличие от муниципальных народных избранников, он подкрепляется, во-первых, институтами и институџиональными практиками; во-вторых, информаџионными и неформально-сетевыми ресурсами. Аичностно-профессиональные характеристики Аепутата при этом отчетливо отходят на третий план, занимая периферийное положение в намеченной конструкщии (табл. 3).

Таблища 3

Функщиональность ресурсов в рамках депутатской деятельности на региональном уровне (экспертные оценки)

\begin{tabular}{l|c|c}
\hline \multicolumn{1}{c|}{ Группы ресурсов } & Оценки экспертов & Средняя оценка \\
\hline Институциональные ресурсы & $5,5,4,4,4,5,4,4,4,4$ & 4,3 \\
Неформально-сетевые ресурсы & $4,4,4,4,3,3,4,4,3,3$ & 3,6 \\
Финансово-экономические ресурсы & $5,4,5,5,4,4,5,5,5,4$ & 4,6 \\
Медиаресурсы & $3,3,3,3,4,4,3,3,4,3$ & 3,2 \\
Личностно-профессиональные ресурсы & $3,3,2,3,3,4,3,2,3,2$ & 2,8
\end{tabular}

В целом эксперты не скмонны напрямую связывать ресурсный потенциал депутата с результативностью его работы, отмечая чрезвычайно широкий спектр факторов, которые оказывают влияние на деятельность народного избранника, определяя ее могику и содержание в тот или иной момент времени. Иными словами, крайне сложно точно определить, кто эффективнее реализует свой мандат - предприниматель, обладающий большими финансово-экономическими возможностями, бывший чиновник, накопивший багаж связей и вовлеченный в систему политических сетей, или проректор вуза, не имеющий серьезных финансовых или политических рычагов, но хорошо знающий проблемы профильной ммя него сферы и обладающий навыками социальных коммуникаций и нормотворчества. В связи с этим нельзя исключать ситуацию, когАа прочно интегрированный в систему политических связей кандидат, привлекательный дмя остальных участников какими-то своими особенными ресурсами, уже на входе в мегислатуру может занять высокие позиции в парламентской иерархии.

Тезис о ситуативности функциональной деятельности депутата можно дополнить мнениями экспертов о том, что опредеменный набор ресурсов нароАного избранника способен потенџиально актуализировать работу в том или ином направлении. Правда, это касается прежде всего тех сфер, которые ориентированы на реализацию представительских функций депутата, в меньшей степени затрагивая нормотворческую деятельность.

Ощутимее всего, по мнению экспертов, просматривается связь ресурсного потенциала депутата с такими неотъемлемыми направлениями его деятельности, как взаимоотношения с избирателями (соџиамьными группами) и 
группами интересов (группами вцияния). Так, выстраиванию коммуникаций с избиратемями наилучшим образом способствуют профессионально- иичностные, финансово-экономические, информационные и институциональные ресурсы. Взаимоотношения с группами интересов Аолжны быть обеспечены финансово-экономическими, неформально-сетевыми и институционацьными ресурсами.

Безусловно, это не значит, что мичностный и профессиональный профиль Аепутата не представцяет никакой значимости при выстраивании отношений с группами вцияния, а, например, вовлеченность народного избранника в систему неформально-сетевых связей и контактов не позволит повысить результативность его взаимоотношений с избирателями. Речь идет исключительно о том, что при реализации разных функциональных задач, стоящих переА Аепутатами, оАни ресурсы имеют преимущества переА Аругими, в результате чего отчетливо просматривается решающее значение одних компонентов и периферийная роль Аругих.

Относительно ресурсного обеспечения нормотворческой деятельности мнения экспертов звучали менее определенно. Как правило, из предложенного

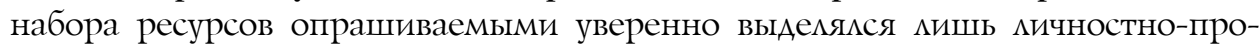
фессиональный сегмент. Эксперты подчеркивали, что именно он, и прежде всего профессионацьные компетенции, позволяют депутату результативно реамизовывать свои полномочия в сфере нормотворчества. Не слишком уверенно респонденты обозначили связь этого функционального блока с неформальносетевыми и институционацьными ресурсами, подчеркивая высокую ситуативность этих корремяџий.

При накладывании формулированных выводов на ресурсные профили депутатов регионацьного и муниципацьного уровней отчетливо просматривается разница в функциональных задачах, на которые ориентированы мегислатуры разных уровней. Если муниципальные народные избранники в большей мере стремятся выстраивать отношения с избирателями, то деятельность региональных парламентариев в приоритетном порядке направлена на решение проблем и цоббирование интересов определенных групп вцияния. Конечно, это во многом условное деление функционала народных избранников, поэтому высказывая оџеночные тезисы, сложно не употреблять слова «преимущественно» или «в большей мере». ОАнако общая картина, на наш взгляА, все же соответствует действительности и выделенные тренды весьма наглядно характеризуют общий функционацьный образ абстрактной муниципальной и абстрактной региональной мегислатуры [7, с. 78-84].

Аействительно, на муниџипальном уровне депутаты в большей мере ориентированы на избирателей своего округа в силу как объективных, так и субъективных факторов. В большинстве случаев обладателями депутатских мандатов в представительных органах местного самоуправления становятся сами жители какого- ибо населенного пункта, которые максимацьно плотно вписаны в сеть социальных коммуникаций. В условиях достаточно небольшой численности избирателей это делает по-настоящему реацьным их стремление реализовать на практике функции представительства 
интересов населения, которое ограничено, пожалуй, мишь финансовыми моментами. Повышают функционацьность системы муниципацьного преАставитецьства мажкоритарные электорацьные схемы, получившие широкое распространение на местном уровне. Учитывая при этом, что число Аепутатских мандатов в местной мегислатуре в значительной части случаев превышает число претендующих на них кандидатов, обладающих Аля этого необходимыми компетенциями ими ресурсами, ориентация на избирателя остается по сути одним из приоритетных повеАенческих ориентиров Аця народного муниципального избранника.

Региональные Аепутаты в Аанном отношении, на наш взгляА, Аействительно не могут ограничивать свою Аеятельность только взаимодействием с избирателями, по объективным обстоятельствам расширяя сферу своих социально-политических коммуникаций. В нее, как минимум, попадает реацизащия ици защита групповых интересов, которые составцяют основу ресурсного потенциала народного избранника. Конечно, избиратели не могут оставаться за рамками депутатской деятельности, но вполне очевидно, что на определенных ее этапах этот функционацьный блок может оказаться не приоритетным.

Еще один вывод, который можно сделать, анацизируя мнения экспертов, касается неравномерности распределения ресурсного потенциала внутри мегислатуры, что позволяет выделить в корпусе народных избранников отдельную группу «ресурсных» депутатов, в руках которых сосредоточены основные ресурсы - финансово-экономические, институциональные, неформально-сетевые, информащионные и кичностно-профессиональные. Важным уточнением в Аанном отношении представцяется то, что, несомненно, каждый депутат опирается на собственный ресурсный потенџиал, однако определение «особого» ресурсного сегмента в депутатском корпусе, по нашему мнению, явцяется важным прежде всего с исследовательской точки зрения.

Такой подход позволяет на основе конкретных индикаторов структурировать депутатский корпус, выдецяя в его составе определенные группы народных избранников на основе их ресурсного профиля, парамлельно решая задачи, связанные с основными направлениями конвертации депутатами размичных ресурсов в политическое влияние. Политическое влияние в Аанном контексте можно рассматривать в качестве производной характеристики ресурсного потенциала депутата, его способности в процессе реализации депутатского мандата выходить за пределы собственных ици групповых интересов, активно позиџионируя себя в роли политического субъекта и реализуя эту роль в общественно-политических и соџиально-экономических коммуникациях. В Аанном отношении интерес представцяют не ресурсы депутата вообще, а способность кандидата конвертировать свой ресурсный потенциал в политическое вцияние.

Группа ресурсных депутатов, обладающих политическим вциянием, не может быть безразмерно широкой. Большинство народных избранников, имеющих какие-то ресурсы, остаются за пределами этого пула, не обладая необходимым уровнем самостоятельности и ориентируясь в рамках своей де- 
ятельности на уже сложившиеся центры политического и экономического влияния. Примечательно в Аанном отношении, что уровень политического влияния Аепутата и его вкАюченность в политический проџесс нецелесообразно соотносить только с руководящими позициями, которые он занимает в мегислатуре или, например, в партийных структурах. Большое значение имеет неформальная структура политического пространства, в которую также вписан каждый народный избранник и позиџии, которые мибо Аобавцяют

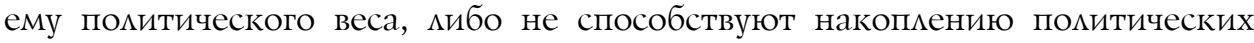
очков.

С Аругой стороны, нецелесообразно, на наш взгляА, напрямую соотносить эффективность депутатской деятельности и принадкежность депутата к особой ресурсной группе. Результативность работы народного избранника можно и нужно оценивать по целому комплексу критериев, которые не привязаны напрямую к имеющимся у него ресурсам. Иными словами, обладающий широкими финансово-экономическими возможностями Аепутат или видный партийный функщионер, имеющий депутатский мандат, совершенно не обязательно начнет активно выступать с законодательными инициативами или будет ориентирован в своей деятельности на открытую коммуникаџию с избирателями. Не очевидно выглядит и обратная ситуация, когда депутат, не обладающий большими ресурсными возможностями, будет находиться на периферии нормотворческой деятельности или работы с избирателями.

Таким образом, пограничный статус (на стыке общественной и государственной сферы ) парламентской деятельности определяет специфику ресурсной базы парламентария, которая сочетает в себе все многообразие общественных ресурсов (финансово-экономических, институџиональных, информационных, неформально-сетевых), а также мичных и профессиональных качеств. Ресурсный профиць депутата имеет пирамидацьную структуру, в фундаменте которой находится базовый ресурс, который наиболее функционален в контексте деятельности конкретного депутата (как в плане достижения мандата, так и в плане его реализаџии). Следующие уровни ресурсной пирамиды представмены вспомогательными ресурсами, которые являются как производными от базового компонента, так и обусловцены возможностями, умениями и способностями парламентария, его вкцюченностью в систему общественных отношений, его статусом в этой системе. Чаще всего в фундаменте ресурсного профиця депутата находятся финансово-экономические и институциональные компоненты, явно Аоминирующие в рейтинге ресурсной функщиональности, на следующем уровне располагаются информационные и сетевые ресурсы, венчают конструкцию мичностно-профессиональные характеристики мичности, которые неотъемлемы от субъекта и выступают его человеческим капиталом.

Ресурсный профиль депутатского корпуса функционально Аифференцирован и обусловлен как уровнем реализации депутатского мандата (федеральный, региональный, муниципальный), так и характеристиками самой депутатской деятельности, аАресными группами, с которыми осушествляется работа (со- 
циальные группы, группы интересов, группы влияния). При решающей роли финансово-экономических ресурсов региональные депутаты в большей степени ориентированы на использование институциональных и сетевых возможностей, муниципальные - мичных и профессиональных качеств.

\section{Библиографический список}

1. Будко Д.А. Политические практики взаимодействия органов региональной власти в современной России: автореф. дис. ... канд. полит. наук. СПб., 2014.

2. Барсукова С.Ю. Теневые правила взаимоотношений политиков и предпринимателей // Журнал институциональных исследований. 2011. Т. 3, № 3. С. 40-56.

3. Сакаева М.М. Бизнесмены в законодательных собраниях регионов - статус как защита и преференция // Социологические исследования. 2016. № 4. С. 142-146.

4. Богатырева Л.В. Механизмы рекрутирования глав региональных законодательных собраний (на примере регионов ЦФО) // Политическая наука. 2012. № 1. С. 175-189.

5. Лобанова А.В. Модели и формы взаимодействия региональной власти, бизнес-структур и гражданского общества // Экономические науки. 2013. № 4. С. 22-26.

6. Человеческий капитал российских политических элит: политико-психологический анализ / под ред. Е.Б. Шестопал, А.В. Селезневой. М., 2012.

7. Крыштановская О.В. Формирование региональной элиты: принципы и механизмы // Социологические исследования. 2003. № 11. С. 78-84. 